\title{
Deposition Rates of Asthma Triggers on Conventional and Enclosed Window Treatments
}

Thorne PS*, Metwali N and Wyland NG

Department of Occupational and Environmental Health, University of Iowa, USA

*Corresponding author: Thorne PS, University of Iowa, Department of Occupational and Environmental Health, 145 N Riverside Dr, 100 CPHB, S341A, Iowa City, IA 52242-5000, USA

Received: April 20, 2021; Accepted: May 20, 2021; Published: May 27, 2021

\begin{abstract}
Environmental interventions are an important element of managing allergies and asthma. Health professionals often recommend that draperies be replaced with window blinds however no data exist on accumulation of inhalant allergens or inflammatory bioaerosols on window treatments. Installing blinds that accumulate less dust may reduce breathing zone exposures when blinds are adjusted if hazardous amounts of bioaerosols are deposited. We sought to determine the rate of accumulation of dust, allergens, bacterial endotoxin and fungal glucan on window blinds of two distinct types mounted on the two types of windows most commonly installed in U.S. homes. The blinds tested were conventional horizontal slat blinds hanging on the inside of the window (roomside blinds) and similar blinds placed between the exterior window glass and an extra pane of glass on the interior side (between-glass blinds). The study was conducted in six households as a paired, repeated measures study. Households were identified for participation, having met the study criteria of children and cats living inside a carpeted home. Standard window blinds accumulated cat allergen, endotoxin and fungal glucan at rates of 5940ng/ $/ \mathrm{m}^{2}, 1910 \mathrm{EU} / \mathrm{m}^{2}$, and $11,360 \mathrm{ng} / \mathrm{m}^{2}$ per month. Between-glass blinds reduced the loading of asthma triggers by $25-$ to 185 -fold. Comparison with clinical thresholds associated with asthma morbidity indicates that room-side blinds accumulate potentially hazardous quantities of asthma triggers.
\end{abstract}

Keywords: Allergens; Asthma triggers; Bioaerosols; Endotoxin; Glucans; House dust

\section{Abbreviations}

ANOVA: Analysis of Variance; ELISA: Enzyme-Linked Immunosorbent Assay; EU: Endotoxin Unit; Fel d1: Felis Domesticus 1 (Cat allergen); GM: Geometric Mean; NHANES: National Health and Nutrition Examination Survey; NSLAH: National Survey of Lead and Allergens in Housing; PBS: Phosphate-Buffered Saline; PF: Pyrogen Free (Free of Endotoxin).

\section{Introduction}

Asthma and wheeze are common adverse respiratory outcomes triggered by exposures to house dust containing inhalant allergens such as those from mites, cockroaches, molds and pets, and inflammatory bioaerosols acting as microorganism-associated molecular patterns, especially bacterial endotoxin and fungal glucans [1-3]. Endotoxin interacts through CD-14, MD-2 and TLR-4 [4] while $\beta$-glucan acts through dectin-1 and TLR-2 [5]. Additionally, endotoxin exposure is associated with the development of chronic obstructive pulmonary disease [6]. Interventions in homes often seek to lower allergens and endotoxin through pet avoidance, institution of integrated pest control, replacement of carpeted floors with cleanable surfaces, installation of high efficiency air filtration and limiting clutter to enhance ease of cleaning [7]. In addition, it is often suggested that draperies and curtains be replaced with window blinds or shades $[8,9]$.

Many studies have examined levels of endotoxins and allergens on floors, beds and upholstery. Two large, nationally representative studies are the National Survey of Lead and Allergens in Housing (NSLAH) and the 2005-2006 rounds of the National Health and Nutrition Examination Survey (NHANES) [1-3,10]. These are the largest studies conducted to date that evaluated exposures to allergens and endotoxin and assessed respiratory outcomes. Additionally, NHANES included serological evaluation of specific IgE directed toward 15 inhalant allergens [11].

While prior studies have evaluated allergen and endotoxin loads on carpets, sofas, bedding, kitchen floors, and bookcases $[1,3,12,13]$, no studies have evaluated window treatments. Specifically, the rate of deposition of allergens and inflammatory agents on window blinds has not been studied and it is not established whether the rate of accumulation differs between types of windows and window treatments. In order to develop evidence-based recommendations for the selection of window treatments for patients with asthma and allergy and to aid in exposure assessment for causal agents, we determined the rate at which cat allergen and microbial agents deposit on two types of window blinds on both casement and doublehung windows. The blinds tested were conventional horizontal slat blinds hanging on the inside of the window (room-side blinds) and a newer type of blind that is placed between the exterior window glass and an extra pane of glass on the interior side (between-glass blinds).

\section{Materials and Methods}

This study was conducted as a paired, repeated measures study of 
the deposition of dust, allergens, endotoxin and glucan on two types of blinds mounted on two types of windows. Six households were identified for participation, having met the study criteria of children and cats living inside a carpeted home. Each agreed to host a window assembly for three months and to allow us to enter their home for the purpose of collecting samples. Sampling occurred from December through February.

Three identical twin casement window units and three identical twin double-hung window units were studied (Designer Series, Pella Corp, Pella, IA) as illustrated in Figure 1. Each unit contained one window with standard aluminum horizontal room-side window blinds, and an identical adjoining window with between-glass window blinds of the same construction (Designer Series, Cordless, Slimshade Blinds, Pella Corp). Each window within the window assembly was $53.3 \mathrm{~cm}$ by $88.9 \mathrm{~cm}$ ( $21 \mathrm{in} \times 35 \mathrm{in})$. The window assemblies were placed in homes on a custom-built stand such that the base of the windows stood at a height of $1 \mathrm{~m}$ above the floor and the windows were held vertically against a wall in a high-traffic, carpeted area. Participants were instructed not to touch or move the window assembly.

Prior to the study, electrostatic wipes and medical examination gloves were tested to establish that they were low in endotoxin as previously described [14]. Wipes for sampling were handled using sterile technique and were cut into $5 \mathrm{~cm}$ by $5 \mathrm{~cm}$ squares from unscented electrostatic cloths (Pledge Grab-it Mitts, SC Johnson and Son, Racine, WI). They were weighed using an ultramicrobalance (Mettler-Toledo MT-5, Columbus, OH). Upon installation, each window blind was thoroughly cleaned with an endotoxin-free, electrostatic wiping cloth to remove any dust, endotoxin and allergen that might be present. The blinds were released to encompass the area of the glass, and the slats were adjusted to a horizontal position (parallel to the floor) for optimal dust collection.

At one-month intervals after window placement, samples were collected from the blinds using pre-weighed, pyrogen-free (PF), electrostatic wiping cloths while wearing PF powder-free Latex medical examination gloves (Safe Skin-PEF, Kimberly-Clark, Dallas, TX). Samples were collected by wiping each slat from right to left, top to bottom, beginning with the room-side blinds. New gloves were used for each window. Wipe samples were placed in bar-coded, $\mathrm{PF}$ extraction vials for transfer to the laboratory. Samples were post-weighed and eluted into $5 \mathrm{ml} \mathrm{PF}$ water with $0.05 \%$ Tween-20, shaken for $1 \mathrm{~h}$, centrifuged at $600 \mathrm{xG}$ at $4^{\circ} \mathrm{C}$ for $20 \mathrm{~min}$, and $500 \mu \mathrm{l}$ of the supernatant was transferred to another tube for endotoxin assay. To $4500 \mu \mathrm{L}$ of the supernatant we added and vortexed $500 \mu \mathrm{l}$ of $10 \mathrm{x}$ Phosphate Buffered Saline (PBS) with 0.05\% Tween-20 for analysis of Fel d1. The pellets were re-eluted in PBS with $0.05 \%$ Tween-20, shaken for $1 \mathrm{~h}$, autoclaved for $1 \mathrm{~h}$ at $120^{\circ} \mathrm{C}$, shaken for another $15 \mathrm{~min}$ and centrifuged at $600 \mathrm{xG}, 4^{\circ} \mathrm{C}$ for $20 \mathrm{~min}$. The supernatant was then transferred to another tube and assayed for glucan.

Samples were analyzed for endotoxin using the kinetic chromogenic Limulus Amebocyte Lysate (LAL) assay [3,15]. Samples were analyzed for Fel d1 using enzyme immunoassay (Indoor Biotechnologies, Charlottesville, VA). Glucan was assayed using a monoclonal antibody specific for (1'3)-b-D-glucan in PBS and $1 \%$ bovine serum albumin in PBS with $0.05 \%$ Tween-20. A custom rabbit polyclonal anti-( $\left.1^{\circ} 6\right)$ branched, $\left(1^{\circ} 3\right)$-b-D-glucan antibody was used for detection followed by incubation with conjugated goat anti-rabbit IgG-HRP and TMB [16-18].

\section{Results and Discussion}

Overall, the geometric mean one-month accumulation per unit area of endotoxin, Fel d1, and fungal glucan on the room-side blinds was $1910 \mathrm{EU} / \mathrm{m}^{2}, 5940 \mathrm{ng} / \mathrm{m}^{2}$ and $11,360 \mathrm{ng} / \mathrm{m}^{2}$, respectively. These values for the between-glass blinds were $37.1 \mathrm{EU} / \mathrm{m}^{2}, 28.2 \mathrm{ng} /$ $\mathrm{m}^{2}$ and $804 \mathrm{ng} / \mathrm{m}^{2}$, respectively. In comparison, in the NSLAH study we measured geometric mean loading in family room floor dust of $17,600 \mathrm{EU} / \mathrm{m}^{2}$ for endotoxin and $342 \mathrm{ng} / \mathrm{m}^{2}$ for cat allergen $[1,2,10]$. However, since vacuum-sampled floor dust is not as readily released to the air as is dust on window blinds, this makes the high cat allergen loading on the room-side blinds even more remarkable.

Comparison of wipe samples collected on all three visits demonstrated a highly significant difference in loading of the endotoxin, Fel d1 and fungal glucan of the between-glass blinds when compared with the room-side blinds (Figure 2). The average ratio of room-side to between-glass blinds for the accumulation of endotoxin was 25 -fold and 52 -fold for the casement and double-hung windows, respectively. Cat allergen demonstrated a ratio of 185 -fold for both and, for fungal glucans, a ratio of 12-fold and 16-fold were observed (Table 1 and Figure 2). Analysis of variance (ANOVA) showed a highly significant difference $(\mathrm{p}<0.0001)$ for endotoxin, Fel d1 and fungal glucan with type of blind but not with window type (Table 1). Only endotoxin showed a significant effect of window type on accumulation rate $(\mathrm{p}=0.011)$ with the double-hung window accumulating more endotoxin. There was no significant interaction of blind and window type and ANOVA for repeated measures showed no effect of month of sampling on the levels of analytes on the blinds.

Figure 2 shows clearly that between-glass blinds accumulated far less dust, endotoxin, cat allergen and glucan than conventional roomside blinds. From these values we can determine that if one were to release the 1-month accumulation of endotoxin, Fel d1 or fungal glucan by raising or agitating the blinds, the average room-side blind would release up to 516EU of endotoxin, 1570ng of Fel d1, 3040ng of

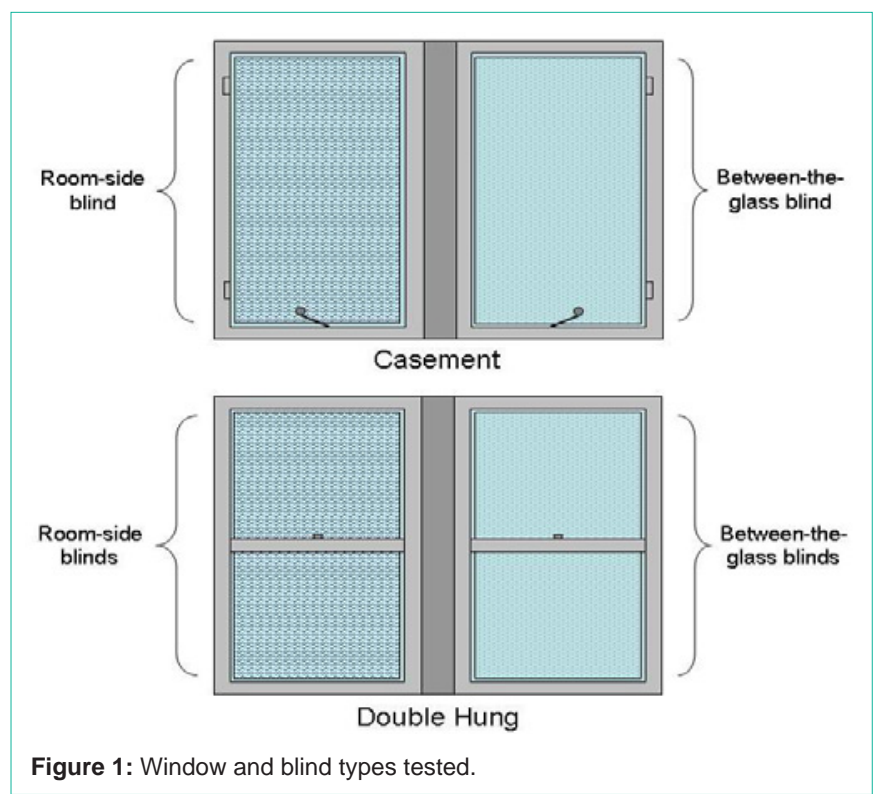


Table 1: Average monthly dust loading and analyte accumulation per unit area for room-side and between-glass blinds for each window type. Geometric mean (10 ${ }^{\text {th }}$, $90^{\text {th }}$ percentile) values are shown for each of the analytes.

\begin{tabular}{|c|c|c|c|c|}
\hline \multirow{2}{*}{ Window } & \multirow{2}{*}{ Blind } & \multicolumn{3}{|c|}{ Analyte $\mathrm{GM}\left(10^{\text {th }}, 90^{\text {th }}\right.$ percentile $)$} \\
\hline & & Endotoxin EU/m² & Fel d1 ng/m² & Fungal Glucan $\mathrm{ng} / \mathrm{m}^{2}$ \\
\hline \multirow{3}{*}{ Casement } & Room-side Blind & $1,420(731,3410)$ & $7,320(407,133000)$ & $8,750(2250,44700)$ \\
\hline & Between-glass Blind & $27.7(15.8,51.9)$ & $39.6(16.5,43.8)$ & $714(431,1162)$ \\
\hline & Ratio $^{+}$ & 25-fold & 185-fold & 12-fold \\
\hline \multirow{3}{*}{ Double Hung } & Room-side Blind & $2,566(2060,3420)$ & $4,814(895,24800)$ & $14,740(10100,56100)$ \\
\hline & Between-glass Blind & $49.6(24.3,81.5)$ & $25.9(8.8,137)$ & $906(418,1350)$ \\
\hline & Ratio $^{+}$ & 52-fold & 185-fold & 16-fold \\
\hline \multirow{2}{*}{ ANOVA $p$ value* } & Blind Type & $<0.0001$ & $<0.0001$ & $<0.0001$ \\
\hline & Window Type & 0.011 & 0.36 & 0.2 \\
\hline
\end{tabular}

${ }^{\dagger}$ Ratio of Room-side to between-glass blinds.

*ANOVA Model: Loge [Analyte] $=$ $ß+\beta 1 \cdot B l i n d+\beta 2 \cdot$ Window $+\beta 3 \cdot$ Window $\times$ Blind $+\xi$ None of the interactions were significant.

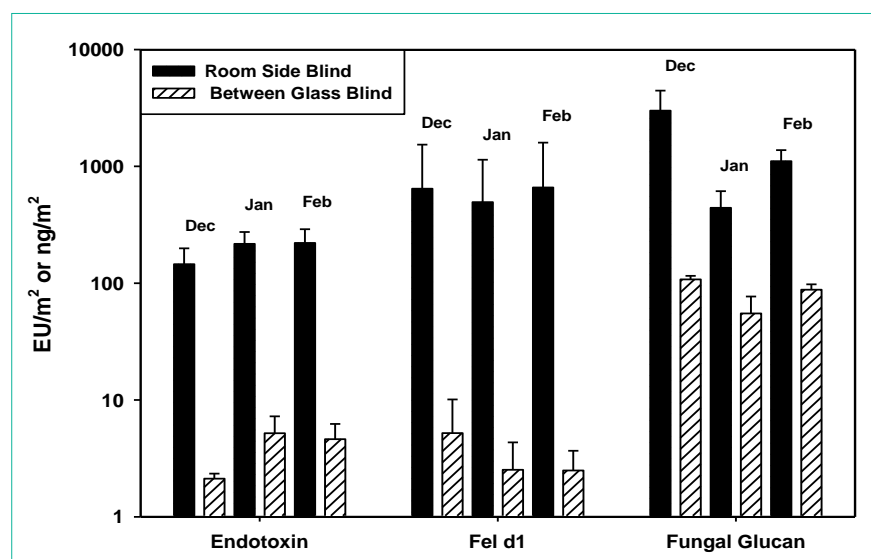

Figure 2: Monthly window blind loading per unit area for endotoxin $\left(E U / \mathrm{m}^{2}\right)$, Fel d1 $\left(\mathrm{ng} / \mathrm{m}^{2}\right)$, and fungal glucan $\left(\mathrm{ng} / \mathrm{m}^{2}\right)$ on two types of blinds. Geometric mean values are shown for each monthly visit. Error bars indicate geometric standard error.

glucan, and $7760 \mu \mathrm{g}$ of dust. In most homes with typical air exchange rates, these levels would be sufficient to induce airway inflammation and trigger allergic symptoms in atopic asthmatics. The clinical threshold associated with asthma morbidity for Fel $\mathrm{d} 1$ measured by ELISA is $8 \mu \mathrm{g} / \mathrm{g}$ [19]. Here we measured $1570 \mathrm{ng}$ Fel $\mathrm{d} 1$ in $7760 \mu \mathrm{g}$ of dust which equates to $202 \mu \mathrm{g}$ Fel d1/g of dust, or 25 -fold higher than the clinical threshold for increased asthma morbidity. Similarly, the potential endotoxin concentration of $66.5 \mathrm{EU} / \mathrm{mg}(516 \mathrm{EU}$ per $7760 \mu \mathrm{g}$ of dust) far exceeds the geometric mean endotoxin concentration found in the 6963 homes measured in the NHANES of $15.49 \mathrm{EU} / \mathrm{mg}$ [3].

These values above contrast sharply with the average betweenglass blinds which would release less than $10 \mathrm{EU}$ of endotoxin, $8.5 \mathrm{ng}$ of Fel d1, 210ng of glucan and less than $35 \mu$ g of dust. Thus, between-glass blinds could reduce exposures to these recognized asthma-triggering agents. We suggest that this type of blind should be considered as part of an extensive indoor intervention for asthmatic individuals of people with severe allergy to household inhalant allergens such as from cats, dogs, mice, mites, cockroaches, or molds.

\section{Conclusion}

This study demonstrates that standard window blinds accumulate bioaerosols such as bacterial endotoxin, fungal glucans and cat allergen at a surprisingly high rate and that agitation of the blinds could result in significant exposures to these biological agents. Newer window styles that encase blinds between glass panes accumulate relatively small amounts of dust and bioaerosols and therefore represent an effective intervention for people who suffer with allergy or asthma.

\section{References}

1. Thorne PS, Kulhánková K, Yin M, Cohn R, Arbes, Jr. SJ, Zeldin DC. Endotoxin Exposure Is a Risk Factor for Asthma: The National Survey of Endotoxin in United States Housing. Am J Respir Crit Care Med. 2005; 172: 1371-1377.

2. Salo PM, Arbes SJ Jr, Crockett PW, Thorne PS, Cohn RD, Zeldin DC. Exposure to Multiple Indoor Allergens in US Homes and its Relationship to Asthma. J Allergy Clin Immunol. 2008; 121: 678-684.

3. Thorne PS, Mendy A, Metwali N, Salo P, Co C, Jaramillo R, et al. Endotoxin Exposure: Predictors and Prevalence of Associated Asthma Outcomes in the United States. Am J Respir Crit Care Med. 2015; 192: 1287-1297.

4. Hađina S, Weiss JP, McCray PB Jr, Kulhankova K, Thorne PS. MD-2Dependent Pulmonary Immune Responses to Inhaled Lipooligosaccharide: Effect of Acylation State of LOS. Am J Respir Cell Mol Biol. 2008; 38: 647654.

5. Yadav M, Schorey JS. The Beta-Glucan Receptor Dectin-1 Functions Together with TLR2 to Mediate Macrophage Activation by Mycobacteria. Blood. 2006; 108: 3168-3175.

6. Mendy A, Salo PM, Cohn RD, Wilkerson J, Zeldin DC, Thorne PS. House Dust Endotoxin Associated with Chronic Bronchitis and Emphysema. Environ Health Perspect. 2018; 126: 037007.

7. Mendy A, Perry SS, Metwali N, Chrischilles EA, Wang K, Thorne PS. Household Endotoxin Reduction in the Louisa Environmental Intervention Project for Rural Childhood Asthma. Indoor Air. 2020; 30: 88-97.

8. Platts-Mills TAE, Vaughan JW, Carter MC, Woodfolk JA. The role of intervention in established allergy: avoidance of indoor allergens in the treatment of chronic allergic disease. J Allergy Clin Immunol. 2000; 106: 787804.

9. WebMD. How to Allergy-Proof Your World.

10. Thorne PS, Cohn R, Mav D, Arbes Jr. SJ, Zeldin DC. Predictors of endotoxin levels in U.S. housing. Environ Health Perspect. 2009; 117: 763-771.

11. Salo PM, Wilkerson J, Rose KM, Cohn RD, Calatroni A, Mitchell HE, et al. Bedroom allergen exposures in US households. J Allergy Clin Immunol. 2018; 141: 1870-1879.e14.

12. Kilburg-Basnyat B, Metwali N, Thorne PS. Effect of deployment time on 
endotoxin and allergen exposure assessment using Electrostatic Dust Collectors (EDC). Ann Occup Hyg. 2015; 59: 104-115.

13. Kilburg-Basnyat B, Peters TM, Perry SS, Thorne PS. Electrostatic dust collectors compared to inhalable samplers for measuring endotoxin concentrations in farm homes. Indoor Air. 2016; 26: 724-733.

14. Thorne PS, Metwali N, Avol E, McConnell R. Surface sampling for endotoxin assessment using electrostatic wiping cloths. Ann Occup Hyg. 2005; 49: 401 406 .

15. Thorne PS. Inhalation toxicology models of endotoxin and bioaerosol-induced inflammation. Toxicology. 2000; 152: 13-23.

16. Blanc PD, Eisner MD, Katz PD, Yen IH, Archea C, Earnest G, et al. Impact of the home environment on adult asthma and rhinitis. J Occup Envir Med. 2005; 47: 362-372
17. Blatter J, Forno E, Brehm J, Acosta-Pérez E, Alvarez M, Colón-Semidey A et al. Fungal exposure, atopy, and asthma exacerbations in Puerto Rican children. Ann Am Thoracic Soc. 2014; 11: 925-932.

18. Choi H, Byrne S, Larsen LS, Sigsgaard T, Thorne PS, Larsson L, et al. Residential culturable fungi, (1-3, 1-6)- $\beta$-d-glucan, and ergosterol concentrations in dust are not associated with asthma, rhinitis, or eczema diagnoses in children. Indoor Air. 2014; 24: 158-170.

19. Gergen PJ, Mitchell H, Calatroni A, Sever M, Cohn R, Salo PM, et al. Sensitization and exposure to pets: The impact on asthma morbidity in U.S. population. J Asthma Clin Allergy: In Practice. 2018; 6: 101-107. 